\title{
Feasibility study of a new unsaturated three-layer landfill cover system
}

\author{
Jason Lim Coo ${ }^{1, a}$, Pui San So ${ }^{1}$, Bruce Chen ${ }^{1}$, Zhou Chao ${ }^{1}$ and Charles Wang Wai $\mathrm{Ng}^{1}$ \\ ${ }^{1}$ Department of Civil and Environmental Engineering, Hong Kong University of Science and Technology, Kowloon, Hong Kong
}

\begin{abstract}
As an improvement of the two-layer cover with capillary barrier effect (CCBE) (i.e. fine-grained soil overlying a coarse-grained soil), a new three-layer landfill cover system is proposed and investigated for humid climate. This new system is to add a fine-grained soil (i.e., clay) underneath a two-layer CCBE (i.e., a silt overlying a gravelly sand layer). The feasibility of this proposed cover system was investigated by conducting a one-dimensional water infiltration test. In addition, transient seepage simulations were carried out to back-analyse the test results and investigate the importance of hydraulic properties of the CCBE on the proposed cover. Based on the infiltration experiment and numerical back-analysis, it is found that no percolation was observed after 48 hours of ponding, which is equivalent to a rainfall return period of greater than 1000 years. However, the upper two-layer CCBE is only effective for a rainfall return period of about 35 years. This implies that the proposed bottom clay layer is needed for humid climate. Numerical parametric simulations reveal that increasing the saturated permeability of the upper finegrained soil by two orders of magnitude $\left(1.4 \times 10^{-6} \mathrm{~m} / \mathrm{s}\right.$ to $\left.2.1 \times 10^{-4} \mathrm{~m} / \mathrm{s}\right)$, the wetting front is still within the clay layer after 12 hours of constant water ponding $(>1000$ year rainfall) and no percolation occurred.
\end{abstract}

\section{Introduction}

Covers that are commonly placed over landfills have been identified as an important component in preventing rainfall infiltration to the buried solid waste after their closure [1-2]. Most modern landfill cover systems utilize geotextile composites and geomembranes to meet the permeability criteria of $10^{-9} \mathrm{~m} / \mathrm{s}$ [3]. It is also common to rely on naturally occurring low permeability materials such as clays. However, landfill covers composed of naturally occurring materials are prone to desiccation induced cracking, which can compromise their integrity and performance [4-5].

Recently, more attention has been given to covers with capillary barrier effects (CCBEs) as an alternative landfill cover system because of their ease of construction, long service life and relatively low cost [67]. Even around 1000 years ago, CCBE has already been applied in burial mounds to avoid water infiltration into the remains [8]. The principle of CCBE utilizes the capillary barrier effect between the two soil layers which consist of a layer of fine-grained soil over a layer of coarse-grained soil. The amount of water infiltrating the system can be minimized due to the coarse-grained soil being less permeable than the fine-grained soil under relatively dry conditions. Although more attention has been paid to CCBEs as an alternative cover system in semi-arid and arid regions, the performance of CCBE under humid climates has so far been unsatisfactory [912].

A new three-layer cover system is proposed and explored to improve a capillary barrier for humid climatic

a Corresponding author: jlcoo@connect.ust.hk conditions such as Hong Kong, Philippines, Columbia and Brazil where annual rainfall of $2,000 \mathrm{~mm}$ is not uncommon. This new system consists of three layers in which a coarse-grained soil layer is placed in between two fine-grained soil layers. The innovation of this threelayer cover system is based on the theory of unsaturated soil mechanics [13] leading to possibly eliminate the use of traditional flexible impermeable membrane for minimizing rainfall infiltration. The feasibility and effectiveness of this three-layer cover system are investigated by conducting a one-dimensional water infiltration test. The experiment is back-analysed and comparisons between experimental data and numerical results are discussed. Moreover, a numerical parametric study is carried out to investigate the importance of saturated permeability of the upper fine-grained soil on the effectiveness of the proposed three-layer system.

\section{Theoretical considerations of the new unsaturated three-layer landfill cover}

Schematic diagrams of a two-layer CCBE and the proposed landfill cover are shown in Fig. 1. As shown in Fig. 1a, CCBE consists of a two-layer soil system that utilizes the distinct differences in the unsaturated hydraulic properties between a fine-grained soil (i.e. silt) and a coarse-grained soil (i.e. gravelly sand). Comparatively, the newly proposed landfill cover system is a three-layer cover system, which consists of a soil layer with a relatively low permeability (i.e., compacted clay layer) that is added underneath a CCBE, as shown in 


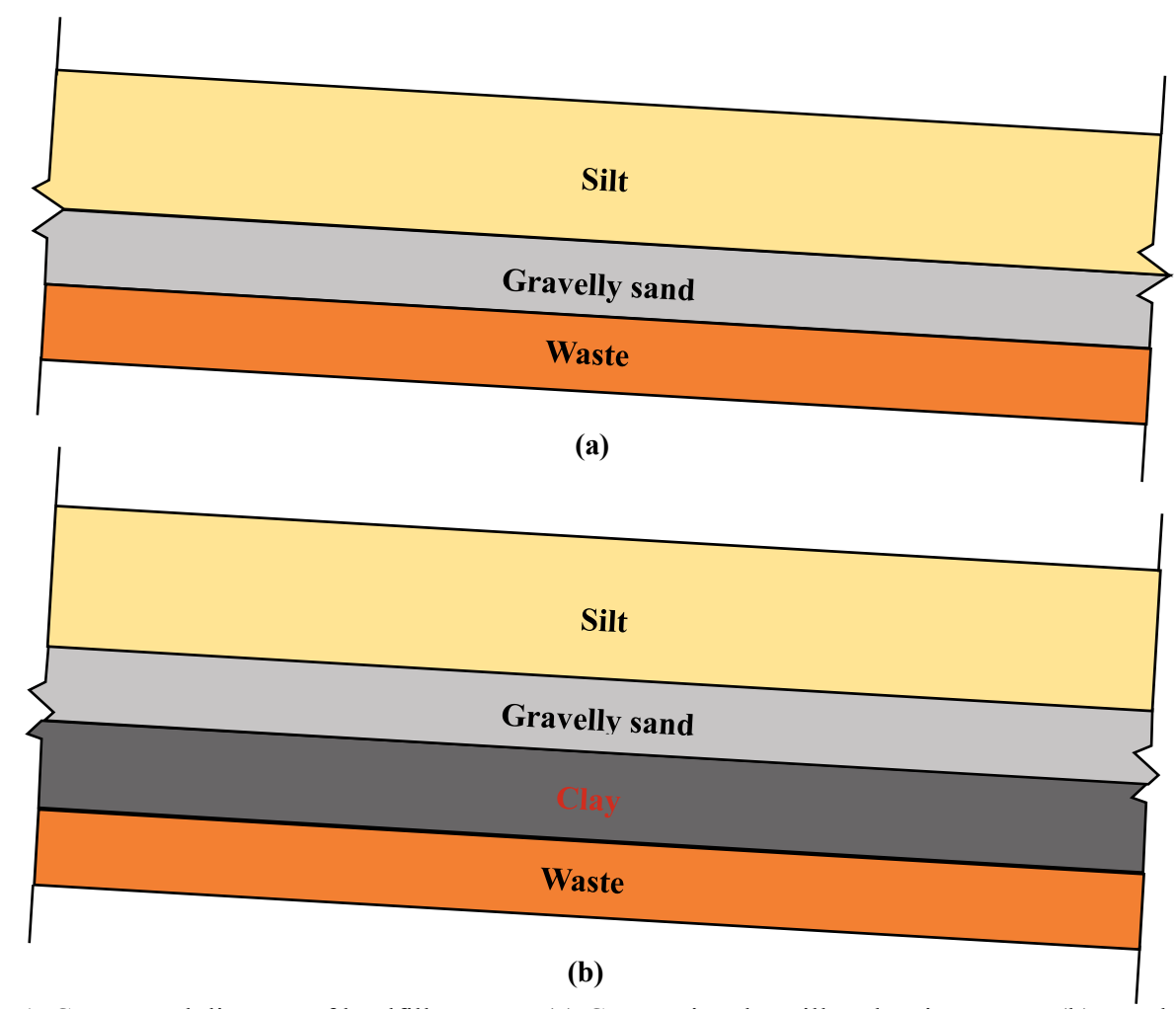

Figure 1. Conceptual diagram of landfill covers : (a) Conventional capillary barrier cover ; (b) Newly proposed landfill cover

Fig. 1b. In this proposed system, water infiltration is minimised by utilizing the capillary barrier effects provided by the two upper soil layers and the low water permeability of the bottom clay layer when it is nearly saturated. On the other hand, the bottom clay layer is protected by the upper two soil layers from desiccation during dry seasons because the upper two soil layers have low water permeability at high suctions (i.e., low relative humidity). The prevention of desiccation crack occurrence on the clay layer can assure the good performance of this alternative cover system for minimising water infiltration. Additionally, the high saturation of the clay layer also minimizes landfill gas emission [14].

\subsection{Principle of reducing water infiltration}

Fig. 2 shows a typical relationship between water permeability and matric suction (i.e. permeability function) of each soil layer.

a. At semi-arid or arid climates, soil suction in the three-layer landfill cover is larger than point $S_{I}$ (shown in the figure), indicating that the cover system is relatively dry. Water permeability of silt is larger than that of gravelly sand and implies that the upper two-layer CCBE is functional. Hence, infiltrated water is then stored in the silt layer and finally removed by evaporation and/or lateral draiange.

b. At humid climates, soil suction in the landfill soil cover is less than point $S_{l}$ (shown in the figure) under heavy or prolonged rainfalls, the cover system is nearly saturated. Water permeability of gravelly sand layer is the highest while that of clay layer is the lowest. Water breakthrough of the upper CCBE occurs when the suction at the interface between the first two layer drop below the water entry value of the gravelly sand layer. Hence, rainfall is able to infiltrate into the gravelly sand layer. However, infiltrated water is prevented by the clay layer due to its low water permeability (see Fig. 2). Infiltrated water may subsequently be drained through the gravelly sand layer and collected into a nearby storage location where water can either be evaporated, discharged or recycled back to the landfill cover.

The combination of the underlying compacted clay layer and the overlying $\mathrm{CCBE}$ makes the proposed landfill cover applicable to all weather conditions.

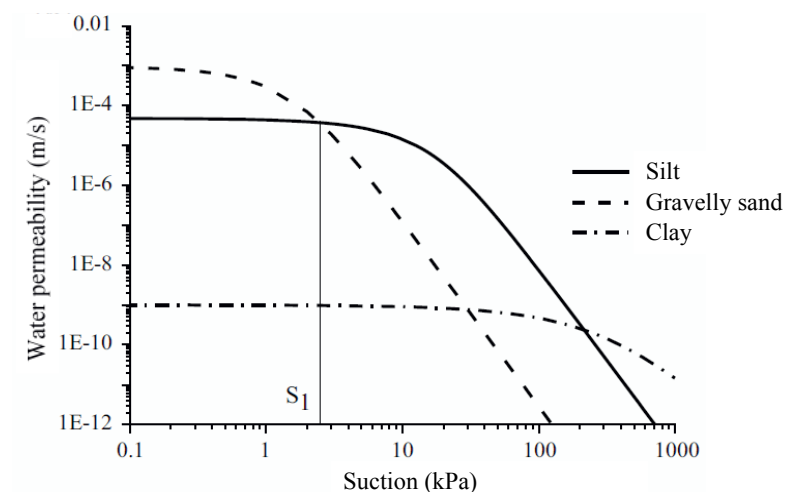

Figure 2. Typical permeability functions of silt, gravelly sand and clay (After $\mathrm{Ng}$ et al. [15]) 


\section{Experimental instrumentation}

apparatus

and

\subsection{1-D soil column}

The performance of the proposed three-layer landfill cover system was assessed using a $1300 \mathrm{~mm}$ height and $140 \mathrm{~mm}$ diameter soil column made of transparent acrylic. The photo of the 1D soil column for water infiltration test is shown in Fig. 3. It is designed to control and measure both the top and bottom boundary flow conditions. At the top boundary upon ponding, constant head infiltration can be achieved by using an electronic weighing scale and a Mariotte's bottle [16]. For the bottom boundary, a valve is connected at the base of the soil column to measure periodically any percolation that occurs during a test.

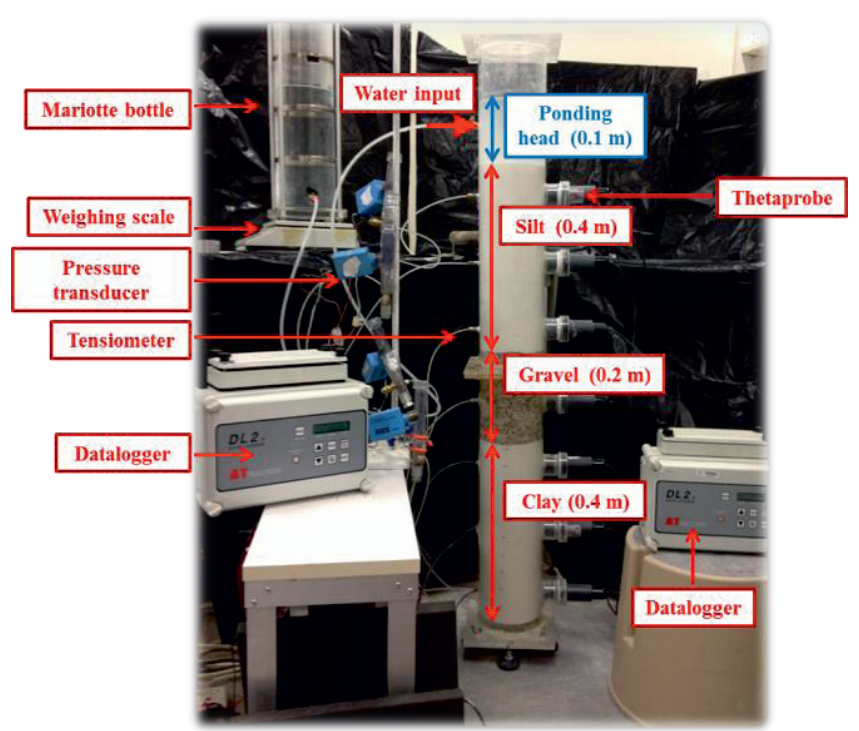

Figure 3. Photo of 1D soil column water infiltration experiment

\subsection{Instrumentation}

The instrumentation consisted of small tip tensiometers and heat dissipation matric water potential sensor to measure soil suctions. Theta-probe soil moisture probes were also used to measure volumetric water content (VWC). Measurements were made at depths of $75 \mathrm{~mm}$, $225 \mathrm{~mm}, 375 \mathrm{~mm}, 525 \mathrm{~mm}, 675 \mathrm{~mm}, 825 \mathrm{~mm}$ and 975 $\mathrm{mm}$ above the base of soil column. Prior to installation, all transducers were properly calibrated.

\section{Test materials and preparation}

\subsection{Test materials}

In this study, silt, gravelly sand and clay were used to form the three-layer landfill cover system. The basic properties of these three soils are shown in Table 1. Compaction curves for the silt and clay were determined in accordance with test method ASTM D698 while ASTM D4253 was used for the gravelly sand. The saturated permeability $\left(\mathrm{k}_{\mathrm{s}}\right)$ of the silt and clay was measured by flexible wall permeameter as described in test method ASTM D5084 while constant-head method as described in test method ASTM D2434 was used for gravelly sand.

Table 1. Basic properties of the soils used in this study.

\begin{tabular}{|l|c|c|c|}
\hline & Silt & $\begin{array}{c}\text { Gravelly } \\
\text { sand }\end{array}$ & Clay \\
\hline $\begin{array}{l}\text { Unified soil classification } \\
\text { system (USCS) }\end{array}$ & $\mathrm{ML}$ & $\mathrm{SP}$ & $\mathrm{CH}$ \\
\hline Specific gravity, $G_{s}$ & 2.61 & 2.62 & 2.52 \\
\hline Liquid limit, LL & 22 & - & 59 \\
\hline Plastic limit, PL & 16 & - & 32 \\
\hline Plasticity Index, PI & 6 & - & 27 \\
\hline $\begin{array}{l}\text { Maximum dry density, } \rho_{d} \\
\left.\text { (kg/m }{ }^{3}\right)\end{array}$ & 1771 & 1494 & 1264 \\
\hline $\begin{array}{l}\text { Optimum moisture } \\
\text { content }(\%)\end{array}$ & 14 & - & 36 \\
\hline $\begin{array}{l}\text { Saturated permeability, } k_{s} \\
(\mathrm{~m} / \mathrm{s})\end{array}$ & $1.4 \times 10^{-6}$ & $9.7 \times 10^{-3}$ & $5.7 \times 10^{-9}$ \\
\hline
\end{tabular}

Water retention curve (WRC) is the relationship between volumetric water content and matric suction of soil. WRC is an important parameter which dictates the water storage of unsaturated soil. In this study, both the wetting and drying WRCs of the soils were obtained by using modified pressure plate apparatus [17]. Subsequently, the wetting WRC data is fitted using the van Genuchten [18] WRC equation. The van Genuchten WRC equation is as follows:

$$
\theta_{w}=\theta_{r}+\left(\theta_{s}-\theta_{r}\right) /\left[(1+\alpha \psi)^{n}\right]^{m}
$$

where $\theta_{w}$ is the volumetric water content at a matric suction $(\psi), \theta_{s}$ is the saturated water content, $\theta_{r}$ is the residual water content, and $\alpha, n$, and $m$ are fitting parameters. The parameter $m$ was constrained as $1-1 / n$ following the standard convention. The WRC data and the fitted wetting WRC are shown in Fig. 4. Best fitting parameters for the wetting WRC based on the van Genuchten equation are presented in Table 2 . The waterentry value of silt and gravelly sand from the WRCs is found to be about $15 \mathrm{kPa}$ and $0.6 \mathrm{kPa}$, respectively. The ratio of water-entry value between these two soils is larger than 10 which creates the formation of a capillary barrier [12].

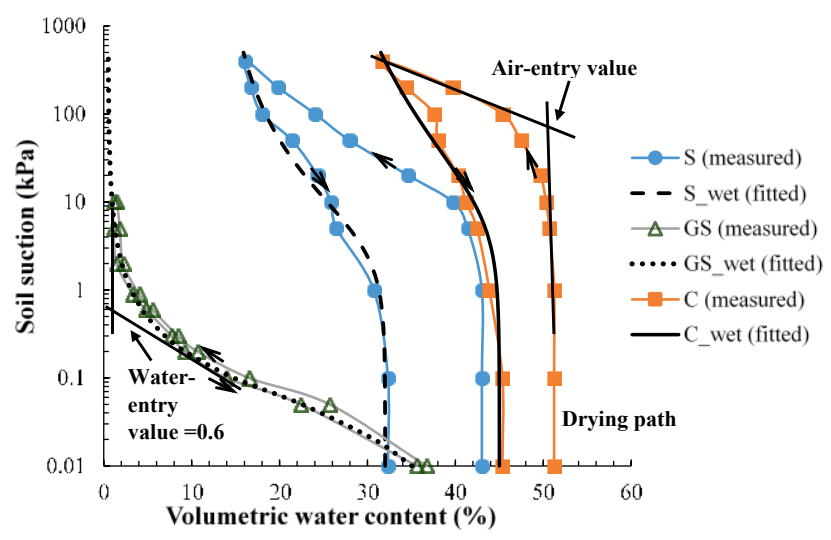

Figure 4. Measured and fitted WRCs of silt (S), gravelly sand (GS) and clay (C) 
Table 2. Fitting parameters of wetting WRC using the van Genuchten [18] equation.

\begin{tabular}{|l|c|c|c|c|c|}
\hline \multirow{2}{*}{ Soil type } & \multicolumn{5}{|c|}{ Fitting parameters } \\
\cline { 2 - 6 } & $\theta_{s}$ & $\theta_{r}$ & $\alpha\left(k P a^{-1}\right)$ & $n$ & $m=1-1 / n$ \\
\hline Silt & 0.33 & 0.03 & 0.5 & 1.17 & 0.15 \\
\hline Gravelly sand & 0.37 & 0.01 & 25 & 1.9 & 0.47 \\
\hline Clay & 0.45 & 0.09 & 0.11 & 1.13 & 0.12 \\
\hline
\end{tabular}

\subsection{Specimen preparation}

The three soil layers; namely, a clay layer, a gravelly sand layer and a silt layer, were compacted successively from bottom to the top of the soil column. The thickness of each soil was $0.4 \mathrm{~m}, 0.2 \mathrm{~m}$ and $0.4 \mathrm{~m}$ for clay, gravelly sand and silt, respectively. The soils were initially mixed with water to reach the optimum moisture content as given in Table 1. The soils were then compacted at their targeted degree of compaction (DOC) or relative density (RD) which is $95 \mathrm{DOC}, 90 \mathrm{RD}$ and $90 \mathrm{DOC}$ for clay, gravelly sand and silt, respectively (see Table 1). A thin film of vacuum grease was also applied to the walls of the column before compaction to minimize any occurrence of preferential flow path during infiltration.

\section{Experimental procedures}

After sample preparation, the soil column was then subjected to water infiltration. The infiltration stage involved imposing a $0.1 \mathrm{~m}$ constant head ponding controlled by a constant-head water supply system. The soil surface was covered during infiltration to minimize evaporation. The test involved measurements of the volume of infiltrated water and water outflow rate as well as profiles of pore water pressure and volumetric water content. Since the soils were initially mixed with water to achieve the respective moisture content, initial suctions were expected to be different between each soil layer in accordance to its WRC (see Fig. 4). The average initial suctions for silt, gravelly sand and clay were found to be $55 \mathrm{kPa}, 20 \mathrm{kPa}$ and $90 \mathrm{kPa}$, respectively. It should be noted that the water infiltration is one dimensional and has no lateral drainage, thus representing a worst case scenario for a landfill cover system under water infiltration.

Most engineering design guidelines are based on rainfall return period [19]. Rainfall return periods at various ponding duration are back-calculated by using the relationship between rainfall depth and duration according to the "Hong Kong Stormwater Drainage Manual" [20]. Further details regarding the conversion of water ponding to equivalent rainfall return period are given in $\mathrm{Ng}$ et al. [21].

\section{Experimental results}

\subsection{Distribution of hydraulic head profiles}

The measured hydraulic head distributions along the soil depth for the water infiltration test are shown in Fig. 5.

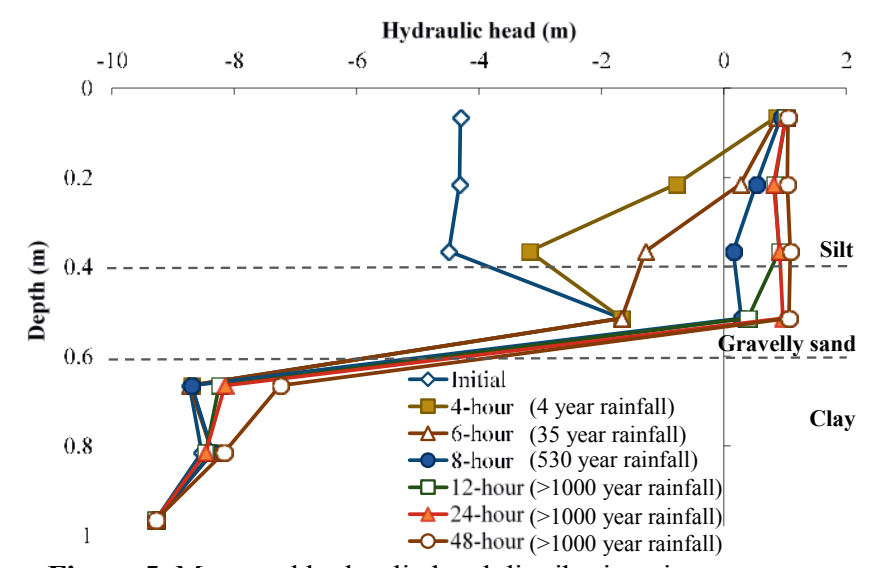

Figure 5. Measured hydraulic head distributions in water infiltration test

The bottom of the soil column, 1 meter below the ground surface, was selected as datum for the hydraulic head calculation. At the initial condition, hydraulic head at the gravelly sand layer is highest followed by the silt layer and then the clay layer. After 4 to 6 hours of ponding (4 and 35 year rainfall), the hydraulic head profile in the silt layer shifted to the right. However, there was no observable hydraulic head change in the gravelly sand. This implies that the gravelly sand layer served as a capillary barrier and prevented the downward flow of water due to its relatively low permeability at this duration. After 8 hours of ponding (530 year rainfall), hydraulic head at the gravelly sand layer shifted to the right while the hydraulic head at the silt layer also shifted further towards the right nearing hydrostatic condition. This shows that water infiltrated into the gravelly sand layer due water breakthrough across the fine-coarse soil interface of the CCBE $[6,22]$. The upper two-layer CCBE was no longer functional after this ponding duration. This phenomenon has been demonstrated by researchers for two-layer CCBEs under one-dimensional conditions [22-24]. After 24 hours of ponding $(>1000$ year rainfall), a hydrostatic condition seems to develop above the clay layer. This is because downward water infiltration is blocked by the inherently low permeability of the clay layer. Therefore, a perched water table occurs and also saturates the soil above the clay layer. Which is consistent with the measured volumetric water content. Further details regarding the measured volumetric water content profile is given in $\mathrm{Ng}$ et al. [21]. It is also observed that even with application of $0.1 \mathrm{~m}$ constant head ponding for 48 hours (>1000 year rainfall), no percolation was measured.

\section{Numerical back-analysis of the infiltration test}

The laboratory experimental data was simulated numerically using CODE_BRIGHT (Coupled Deformation Brine, Gas and Heat Transport) [25]. The model was one-dimensional with the same geometry as the actual experimental conditions. Similar boundary conditions as those applied in the experimental column test were imposed. The numerical simulation results of the infiltration tests were verified by comparing them 
with the laboratory experimental data. The wetting WRC (see Fig. 4 and Table 2) and unsaturated permeability functions (see Fig. 2) of the soils were used in the simulation.

The unsaturated permeability functions were predicted from the measured wetting WRC by using in conjunction the van Genucthen-Mualem equation [18, 26]. The equation is as follows:

$k_{r}(\psi)=k_{w}(\psi) / k_{s}=\left\{1-(\alpha \psi)^{n-1}\left[1+(\alpha \psi)^{n}\right]^{-m}\right\}^{2} /\left[1+(\alpha \psi)^{n}\right]^{m / 2}$

where $k_{w}(\psi)$ is the unsaturated coefficient of permeability at a matric suction $(\psi), k_{s}$ is the saturated permeability coefficient and $\alpha, n$, and $m$ are fitting parameters from the van Genucthen [18] equation best fit to the WRC.

\subsection{Comparison between experiment and computed results}

Fig. 6 shows comparisons between the pore water pressure profiles, which were obtained from the finite element analysis and the measured results during the experiment. The numerical simulation results show a good agreement with those observed in the laboratory experiments. Upon application of $0.1 \mathrm{~m}$ constant ponding head for the first 6 hours, infiltration occurred mainly in the silt layer but not in the gravelly sand layer as reflected by the fact that measured and simulated pore-water pressure remained unchanged in the gravelly sand layer. After 8 hours of ponding, the simulated pore-water pressure at the gravelly sand layer increased, which is consistent with the movement of pore-water pressure measured from the experimental test. This infers that water has already infiltrated into the gravelly sand layer and the upper two-layer capillary barrier is no longer effective. Due to continuous application of ponding it can be observed that after 24 hours a hydrostatic condition seems to develop above the clay layer. After 48 hours of ponding, both simulation and measurement demonstrates that only the upper portion of the clay layer shows an increase of pore-water pressure. This indicates that due to the addition of clay layer underneath a two-layer CCBE, infiltrated water require a rather long duration to reach the deeper portion of the clay layer. Thus percolation can be prevented even for rainfalls greater than 1000 year return period.

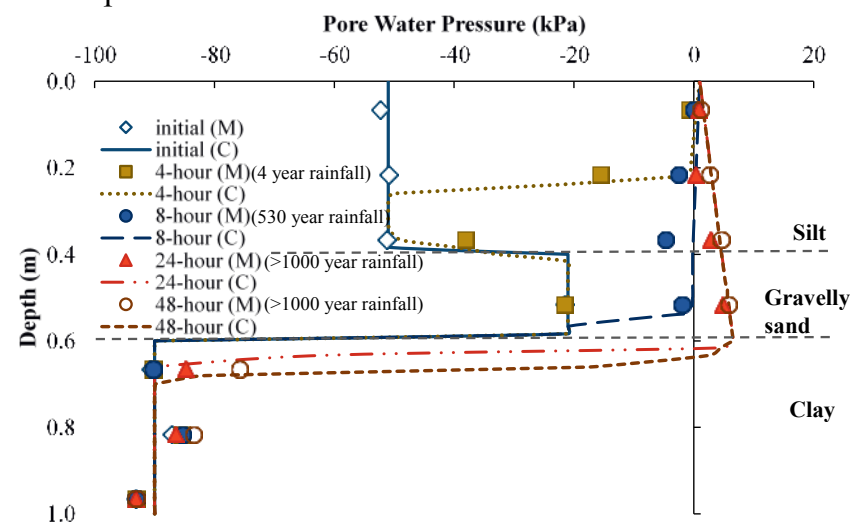

Figure 6. Comparisons between measured (M) and computed (C) pore water pressure profiles in infiltration test

\section{Parametric study}

According to Albrecht [27], who carried out laboratory permeability test of landfill covers, it is reported that saturated permeability of surface soils in landfills increases after it undergoes several wetting and drying cycles due to desiccation cracks. Hence, an additional parametric study is carried out to investigate the importance of permeability of the upper fine-grained soil on the effectiveness of the proposed three-layer system. The intention of this study was to take into account the influence of desiccation cracks on the upper fine-grained soil. It should be noted that this is just a simple sensitivity study and two additional higher values of $\mathrm{k}_{\mathrm{s}}$ typically utilized in the upper fine-grained soil were chosen from the literature. The saturated permeability $\left(\mathrm{k}_{\mathrm{s}}\right)$ of the finegrained soil were $1.4 \times 10^{-6} \mathrm{~m} / \mathrm{s}$ (this study), $2.0 \times 10^{-5} \mathrm{~m} / \mathrm{s}$ [23] and $2.1 \times 10^{-4} \mathrm{~m} / \mathrm{s}$ [28]. The shape of the permeability function has been kept the same within this study.

\subsection{Influence of upper fine-grained soil saturated permeability}

Fig. 7 shows a series of computed pore water pressure profiles of constant head ponding at 12 hours with different upper fine-grained soil $\mathrm{k}_{\mathrm{s}}\left(1.4 \times 10^{-6} \mathrm{~m} / \mathrm{s}, 2.0 \times 10^{-5}\right.$ $\mathrm{m} / \mathrm{s}$ and $\left.2.1 \times 10^{-4} \mathrm{~m} / \mathrm{s}\right) .12$ hours $(>1000$ year rainfall) represent the time that the upper two layer CCBE is no longer effective and for the wetting front to reach clay layer with respect to the reference upper fine-grained soil $\mathrm{k}_{\mathrm{s}}$ used in the experiment. For all $\mathrm{k}_{\mathrm{s}}$ values, a positive pore water pressure develops at the upper two-layer CCBE. The $k_{s}$ of the upper fine-grained soil has some influence on the pore water pressure distribution. The larger the value of $\mathrm{k}_{\mathrm{s}}$, the downward flow of water is easier, and hence water breakthrough of the CCBE occurs earlier [10]. After this event, water starts to infiltrate into the gravelly sand layer and eventually into the clay layer. Thus, a deeper wetting front in the clay layer is observed as the value of $\mathrm{k}_{\mathrm{s}}$ becomes larger. Additionally, due to earlier water breakthrough of the CCBE, a hydrostatic condition seems to develop for the two additional values of $\mathrm{k}_{\mathrm{s}}\left(2.0 \times 10^{-5} \mathrm{~m} / \mathrm{s}\right.$ and $\left.2.1 \times 10^{-4} \mathrm{~m} / \mathrm{s}\right)$ with respect to the reference $\mathrm{k}_{\mathrm{s}}\left(1.4 \times 10^{-6} \mathrm{~m} / \mathrm{s}\right)$. Nonetheless, the wetting front

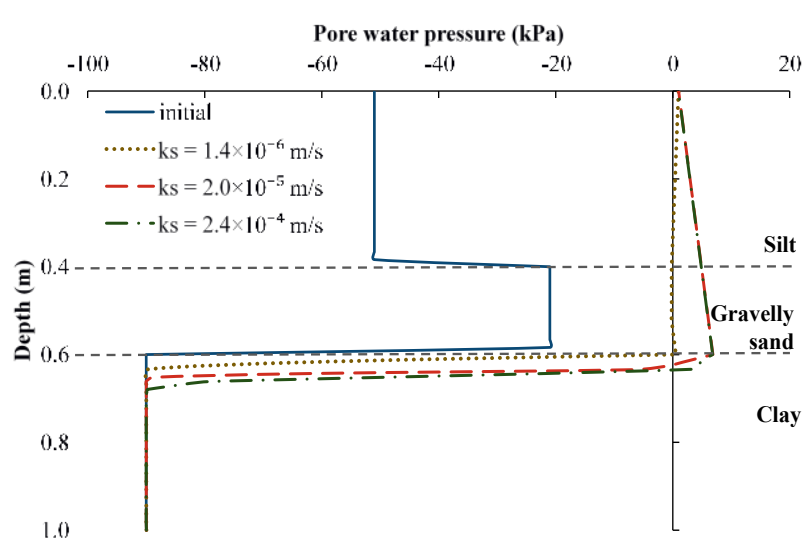

Figure 7. Computed pore water pressure profiles in infiltration test at elapsed time of 12 hours ( $>1000$ year rainfall) with respect to different saturated permeability $\left(\mathrm{k}_{\mathrm{s}}\right)$ of the upper finegrained soil 
for the largest value of $\mathrm{k}_{\mathrm{s}}\left(2.1 \times 10^{-4} \mathrm{~m} / \mathrm{s}\right)$ is still within the clay layer and is approximately $700 \mathrm{~mm}$ below the ground surface. This suggests that the clay layer had yet to be fully saturated and thus no percolation happened. This further indicates that the three-layer landfill cover system performs satisfactorily despite the increase of $\mathrm{k}_{\mathrm{s}}$ for the upper fine-grained soil.

\section{Summary and conclusions}

An alternative three-layer landfill cover system was proposed and explored for regions with humid climates where annual rainfall exceeds $2000 \mathrm{~mm}$. The fundamental modification of this alternative system is the addition of a clay layer underneath a conventional twolayer capillary barrier system. This bottom clay layer is intended to function as an impeding layer to minimise percolation into the underlying waste when water breakthrough occurs into the upper two-layer capillary barrier during heavy and prolonged rainfalls. The results of the numerical analyses and infiltration tests using onedimensional soil column showed that no percolation was observed after 48 hours of constant ponding, which is equivalent to a rainfall return period of greater than 1000 years. However, the upper two-layer capillary barrier is only effective for a rainfall return period of about 35 years. This means that the proposed bottom clay layer is necessary for humid climates. Numerical parametric simulations reveal that increasing the saturated permeability of the upper fine-grained soil by two orders of magnitude $\left(1.4 \times 10^{-6} \mathrm{~m} / \mathrm{s}\right.$ to $\left.2.1 \times 10^{-4} \mathrm{~m} / \mathrm{s}\right)$, the wetting front is still within the clay layer after 12 hours of constant water ponding and no percolation occurred. Both experimental investigation and numerical simulations showed that the proposed three-layer cover system is a promising alternative landfill cover system for humid climates.

\section{Acknowledgment}

The authors would like to acknowledge the research grant (2012CB719805) from the National Basic Research Program (973 Program) provided by the Ministry of Science and Technology of the People's Republic of China and research grant HKUST6/CRF/12R provided by the Research Grants Council (RGC) of the Hong Kong Special Administrative Region.

\section{References}

1. U.S. EPA, Design and Construction of RCRA/CERCLA Final Covers (Seminar publication, EPA/625/4-91/025, 1991)

2. C.H. Benson, M.A. Barlaz, D.T. Lane, J.M. Rawe, Waste Manage. 27(1), 13-29 (2007)

3. U.S. EPA, Solid Waste Disposal Facility Criteria (Technical manual, EPA530-R-93-017, Washington DC, 1993)

4. S. Melchior, Land Contam. Reclam. 5(3), 209-216 (1997)
5. W.H. Albright, C.H. Benson, G.W. Gee, T. Abichou, E.V. McDonald, S.W. Tyler, S.A. Rock, Geotech. Geoenviron. Eng. 132(11), 1393-1403 (2006)

6. B. Ross, Water Resour Res. 26(1), 2625-2629 (1990)

7. S.F. Dwyer, Water Balance Measurements and Computer Simulations of Landfill Covers ( $\mathrm{PhD}$ Thesis, The University of New Mexico, 2003)

8. K. Watanabe, Proc., Joint International Waste Management Conference, Vol 1, 567-571 (1989)

9. C.E. Morris, J.C. Stormont, J. Geotech. Geoenviron. Eng. 123(12), 1057-1065 (1999)

10. M.V. Khire, C.H. Benson, P.J. Bosscher, J. Geotech. Geoenviron. Eng. 126(8), 695-708 (2000)

11. W.H. Albright, C.H. Benson, G.W. Gee, J. Environ. Qual. 33(6), 2317-2332 (2004)

12. H. Rahardjo, D. Tami, E.C. Leong, Proc., $2^{\text {nd }}$ International Conference on Problematic Soils, 3954 (2006)

13. C.W.W. Ng, B. Menzies, Advanced Unsaturated Soil Mechanics and Engineering (Taylor and Francis, London and NY, 2007)

14. C.W.W. Ng, Z.K. Chen, J.L. Coo, R. Chen, C. Zhou, Waste Manage. 44, 155-163 (2015)

15. C.W.W. Ng, J. Liu, R. Chen, J.L. Coo, Environ. Earth Sci. 74(5), 4419-4429 (2015).

16. E.L. McCarthy, Science 80(100)

17. C.W.W. Ng, Y.W. Pang, J. Geotech. Geoenviron. Eng. 126(2), 157-166 (2000)

18. M.T. van Genucthen, Soil Sci. Soc. Am. J. 44(5), 892-898 (1980)

19. GEO, Geotechnical Manual for Slopes (Geotechnical Engineering Office, Hong Kong, 2011)

20. DSD, Stormwater Drainage Manual (Drainage Services Department, Hong Kong Government, 2013)

21. C.W.W. Ng, J.L. Coo, Z.K. Chen, R. Chen, J. Environ. Eng. (Accepted)

22. H. Yang, H. Rahardjo, E.C. Leong, J. Hydrol. Eng. 41(5), 908-920 (2006)

23. J.S. McCartney, J.G. Zornberg, Can. Geotech. J. 47(11), 1201-1213 (2010)

24. J.C. Stormont, C.E. Anderson, J. Geotech. Geoenviron. Eng. 125(8), 641-648 (1999)

25. S. Olivella, J. Carrera, A. Gens, E.E. Alonso, Transp. Porous Media 15(3), 271-293 (1994)

26. Y. Mualem, Water Resour. Res. 12(3), 513-522 (1976)

27. B. Albrecht, Effect of Desiccation on Compacted Clays (MS thesis, University of Wisconsin-Madison, 1996)

28. S.W. Webb, Water Resour. Res. 22(8), 1855-1859 (1997) 